DAVID F. BRADFORD Princeton University

and National Bureau of Economic Research

\title{
Tax Neutrality and the Investment Tax Credit
}

THIS PA P E R concerns the question of how the rules for calculating the investment tax credit and the associated rules for calculating depreciation allowances for tax purposes should be structured to assure the "appropriate" relationship between the subsidy granted to longlived assets and that to short-lived assets. Under the U.S. federal income tax a credit is allowed against tax liability equal to a certain fraction of the cost of qualifying investments. The fraction depends on the durability of the asset, as measured by its "useful life." For assets with useful lives of less than three years no credit is allowed; assets with lives of between three and five years qualify for a credit of $3 \frac{1}{3}$ percent; those with lives of between five and seven years, $62 / 3$ percent; and those with lives of seven or more years, 10 percent. $^{1}$ This credit against tax is ignored in the calculation of tax allowances for depreciation, which are based on the historical cost of the asset. ${ }^{2}$

The author would like to acknowledge helpful discussions with Seymour Fiekowsky, Harvey Galper, and Roger Gordon on the subject of this paper. Any opinions expressed are those of the author and not of Princeton University or the National Bureau of Economic Research.

1. This description neglects the extra credit that is allowed, contingent on employer contributions to a qualifying employee stock ownership plan.

2. The Long Amendment (named for the chairman of the Senate Finance Committee, Senator Russell B. Long), a part of the original investment credit enacted in 1962 but subsequently repealed with retroactive effect, required subtraction of the investment credit from the purchase price of the asset in the calculation of depreciation allowances. 
Both of these features of the tax rules have a bearing on the choice by an investor between long- and short-lived assets. The increasing rate of tax subsidy under the investment credit favors long-lived assets by comparison with a flat-rate credit, while the neglect of the credit in calculating depreciation allowances favors short-lived assets (for which the depreciation allowance is a more important element in the cash flow). There is considerable confusion about which of these two biases in the rules is the right one. ${ }^{3}$ In reviewing the literature on this issue Sunley focused on the question of whether the investment credit should vary with the durability of the asset purchased. ${ }^{4} \mathrm{He}$ concluded that neutrality requires a subsidy rate increasing with the useful life of the asset in a way qualitatively similar to that prescribed in present U.S. law.

This paper develops Sunley's discussion through the use of simple formal models of the yield from investment. A principal conclusion is a qualified confirmation of Sunley's view that neutrality requires the rate of credit to increase with asset life. Furthermore, if tax rules are otherwise fundamentally correct, the cost basis for depreciation allowances should be net of investment tax credit. ${ }^{5}$ Even with this condition, however, it is not possible in general to present a neutral rule for calculating the investment credit independently of the rate of interest and of the detailed pattern of returns from the asset.

The essential principle underlying the conclusions of this paper is that efficiency requires equality of the before-tax and before-subsidy rates of return on investments in assets of various durabilities. To obtain an efficient allocation, subsidy and tax rules must be appropriately related to the durability of the assets. Although it may be possible to design such a relationship in the case of the investment credit applied to assets within some limited class of durability characteristics (for example, within the class of assets that lose a constant fraction of their value every year), no simple rule will give appropriate results for all classes. In particular, the cases examined il-

3. It is sometimes argued that the increasing subsidy for longer-lived assets is justified primarily as a rough offset to the failure to use as the basis for depreciation the true effective cost to the investor, namely, the after-tax credit cost.

4. Emil Sunley, Jr., "Tax Neutrality between Capital Services Provided by LongLived and Short-Lived Assets," in U.S. Department of the Treasury, OT A Papers, vol. 1: Compilation of OTA Papers (Government Printing Office, 1978).

5. That is, the Long Amendment is necessary. It is not suggested that the depreciation rules available under U.S. law are correct; they certainly are inadequate in a time of inflation. 
lustrate the way simple rules relating investment credit to the single dimension, "asset life," go wrong as the actual pattern of returns varies from exponential decay to point output, to constant flow output. $^{\text {i }}$

The analysis takes up in turn three special models of investment opportunities: point input, exponentially declining output; point input, point output; and point input, constant flow output. The first is perhaps the most familiar to economists. Exponential decay is much the most convenient depreciation assumption to make in models of economic growth. It has also been common in the tax literature. The very analytical convenience that makes exponential depreciation attractive, however, may lead to neglect of the question of how conclusions are affected by it. Hence a section of the paper is devoted to the alternative investment models mentioned.

For the most part I assume that taxpayers use true "economic" depreciation in calculating income subject to tax. This assumption is important because it assures that if the investment subsidy can be made "neutral," the income tax system, whether proportional or progressive, will influence investment only via its effect on savings and not via the composition of the capital stock. ${ }^{8}$ It is necessary in this context to be clear about the definition of economic depreciation, an issue that calls for a digression on "recapture" and the treatment of secondhand assets.

\section{Taxes and Investment Credit in an Exponential World}

The model of investment made familiar by Jorgenson is most naturally interpreted as a world in which the quantity of capital consists of a number of identical physical units (for example, shovels

6. Such shortcomings of simple approximating rules need not imply the procedures should be changed. The relative performance of different rules of thumb is the issue. It does appear that for purposes of subsidizing investment a partial write-off for tax purposes would be both simpler and superior to present practices from the point of view of neutrality. This point is developed more fully by Harberger in this volume.

7. See, for example, Robert E. Hall and Dale W. Jorgenson, "Tax Policy and Investment Behavior," American Economic Review, vol. 57 (June 1967), pp. 391414.

8. See Paul A. Samuelson, "Tax Deductibility of Economic Depreciation to Insure Invariant Valuations," Journal of Political Economy, vol. 72 (December 1964), pp. 604-06. 
or machines).$^{9}$ Each machine produces a fixed output per period. As a result of physical deterioration, a fixed proportion of the stock of machines disappears each period.

In this world the quantity of capital of any particular type is readily understood. Whereas in a more general case it may not be obvious what quantity of capital I own when I have a one-year-old machine, it is clear how many units I own if they consist of a fraction of the previous year's stock of identical machines.

The "rental cost of capital," $c$, also has a ready interpretation in this model: it is the price paid for the use of one machine for one period. In a competitive system this price will clear the market for machine services, equating the quantity supplied by capitalists to the quantity demanded by firms for use in production.

Particular interest attaches to the relationship in equilibrium between the rental cost of capital, the market rate of interest, $i$, and the price, $q$, of a newly produced machine. Under my assumptions, in the absence of taxes the capitalist receives a cash flow from a machine, $c \cdot \exp [-\delta s]$, where $\delta$ is the fractional rate at which machines disappear and $s$ is the age of the machine. The capitalist able to borrow and lend at the market rate of interest, $i$ (I neglect uncertainty throughout), will be indifferent about purchasing another machine when

$$
q=c \int_{0}^{\infty} \exp [-(i+\delta) \xi] d \xi
$$

or

$$
c / q=i+\delta .
$$

If an income tax is imposed at proportional rate, $u$, the capitalist will evaluate net-of-tax cash flows at his after-tax rate of return from lending, $(1-u) i .^{10}$ The cash flow from purchasing a machine will also be affected by (1) any investment tax credit assumed equal to $k$ per unit invested, and (2) depreciation allowances assumed granted

9. See Hall and Jorgenson, "Tax Policy and Investment Behavior."

10. The analysis that follows is most easily understood as applying to direct investment by individuals. It will apply to corporations as well if it is assumed that the same marginal rate of tax applies to shareholder equity returns and the bond interest of those shareholders. For a fully satisfactory treatment, however, one would have to resolve analytical problems (for example, the existence of many different shareholder tax rates) beyond the scope of this paper. 
at rate $D(s) \cdot q$, where $s$ is asset age. ${ }^{11}$ Equilibrium with wealth maximization now implies ${ }^{12}$

$$
\begin{aligned}
(1-k) q= & (1-u) c \int_{0}^{\infty} \exp [(-\delta-i(1-u)) \xi] d \xi \\
& +u q \int_{0}^{\infty} \exp [-i(1-u) \xi] D(\xi) d \xi
\end{aligned}
$$

or

$$
c / q=[i(1-u)+\delta][1-k-u Z(i(1-u))] /(1-u)
$$

where

$$
Z\left(r^{a}\right)=\int_{0}^{\infty} \exp \left[-r^{a} \xi\right] D(\xi) d \xi
$$

is the present value to the taxpayer of the tax-allowed depreciation deductions on one unit of tax basis if $r^{a}$ is the taxpayer's after-tax return. For easier comparison with the equilibrium condition without taxes this can alternatively be written as

$$
c / q=\left(r^{a}+\delta\right)\left[1-k-u Z\left(r^{a}\right)\right] /(1-u) .^{13}
$$

When the depreciation schedule, $D(s)$, is applied to the effective purchase price, $(1-k) q$, rather than the nominal historical price, $q$, the equilibrium relationship between $c$ and $q$ (expression 1 ) is replaced by

$$
c / q=\left(r^{a}+\delta\right)\left[1-u Z\left(r^{a}\right)\right](1-k) /(1-u) .
$$

11. This roughly describes present law.

12. These formulas apply for an investment held forever. Hence it is not necessary to be concerned about the proceeds of sale of the asset. This will only be wealth maximizing appropriate tax rules, even in the steady state with constant $c, q, a$, and $i$, as is discussed further below.

13. As the derivation indicates, because tax rates and hence after-tax rates of return vary among taxpayers, the supply price of machine services may vary from taxpayer to taxpayer. This variation is incompatible with equilibrium in the market for machine services. Such inconsistency may be resolved by sorting out asset types by the tax brackets of their owners, as occurs in tax shelter situations. In what follows, to avoid having to deal with this, assume $"$ is the same for all taxpayers. For an analysis of how opportunities for profit are eliminated when taxpayers face different rates, see David F. Bradford, "The Tax System, Saving, and Capital Formation," in George von Furstenberg, ed., Capital Investment and Saving, vol. 2: The Government and Capital Formation (Ballinger, 1980). 


\section{True Depreciation: A Conceptual Problem}

What is the rate of economic or true depreciation experienced by investors under either of these systems? There is a certain ambiguity about this question arising out of the subsidy, $k$, and the possible tax advantage or disadvantage due to the difference between the depreciation allowed in calculating the tax and that actually occurring.

As far as the replacement cost of the asset is concerned, the matter is clear. Under the exponential decay assumption the pattern of physical depreciation is described by

$$
D^{*}(s)=\delta \exp (-\delta s) .
$$

Because in this case the actual decay takes the form of a reduction in the number of identical physical machines, the decline in replacement cost value (the price paid by the buyer before receiving any credit) must follow this pattern as well. The replacement cost of a machine of age $s$ and of type $\delta$ must be given by $q \exp (-\delta s)$, and the instantaneous loss at that age is given by $D^{*}(s) \cdot q$.

This would describe the path of the demand price of the asset if a purchaser of the used asset could obtain the same tax and subsidy treatment as if he had purchased the same number of identical but newly produced machines. The value to the original purchaser of the asset will generally be less than this amount because tax and credit advantages will have already been realized. Special rules are required to prevent, for example, the buyer of a new machine from obtaining the investment credit and then immediately reselling his asset to another purchaser, who in turn receives the same credit. The "recapture" rules of the U.S. tax system, applicable to the investment credit and certain forms of accelerated depreciation, as well as special rules for the treatment of used assets, are designed to moderate such taxmotivated transactions. ${ }^{14}$ To avoid complexity, I assume that these rules are perfect so that the tax system has no influence on the desired time-since-acquisition structure of a capitalist's stock of machines. ${ }^{15}$

ECONOMIC DEPRECIATION TO THE HOLDER. What is the path of asset value to the holder of one of the machines who plans to keep it

14. See Gerard M. Brannon and Emil M. Sunley, Jr., "The 'Recapture' of Excess Tax Depreciation on the Sale of Real Estate," National Tax Journal, vol. 29 (December 1976), pp. 413-21, for an interesting and surprising discussion of recapture rules in the U.S. income tax.

15. Recall that the assumption is that all machines having the same durability coefficient, $\delta$, are identical, regardless of the time since construction. 
perpetually? I refer to the rate of decrease of asset value along this path as "economic depreciation." It will in general depend on the tax rules, including the depreciation allowances. Hence to use economic depreciation for tax purposes requires finding a fixed point: economic depreciation is a function of tax depreciation; a rule is sought that will make tax depreciation equal economic depreciation.

Let $v(s)$ denote the value of a machine as a function of the time, $s$, since original construction and purchase, and let $H(s)$ represent the schedule of depreciation allowances-as distinguished from the schedule of depreciation rates, $D(s)$, against basis-for tax purposes. Then the cash flow from the asset at $t$ is

$$
(1-u) c \exp (-\delta t)+u H(t)
$$

so that

$$
\begin{aligned}
v(s)= & (1-u) c \int_{0}^{\infty} \exp (-\delta \xi) \exp \left[-r^{a}(\xi-s)\right] d \xi \\
& +u \int_{s}^{\infty} H(\xi) \exp \left[-r^{a}(\xi-s)\right] d \xi .
\end{aligned}
$$

The expression for depreciation is found by differentiating expression 4 to obtain

$$
\begin{aligned}
-v^{\prime}(s)= & (1-u) c \exp (-\delta s)+u H(s)-(1-u) c r^{a} \int_{s}^{\infty} \exp (-\delta \xi) \\
& \exp \left[-r^{a}(\xi-s)\right] d \xi+u r^{a} \int_{s}^{\infty} H(\xi) \exp \left[-r^{a}(\xi-s)\right] d \xi \\
= & \text { cash flow at } s-r^{a} \nu(s) .
\end{aligned}
$$

If the value of depreciation in this sense is used for tax purposes (call this schedule $H^{*}(s)$ ), then using $-v^{\prime}(s)=H^{*}(s)$ :

$$
(1-u) H^{*}(s)=(1-u) c \exp (-\delta s)-r^{a} v(s) .
$$

Differentiating,

$$
(1-u) H^{* \prime}(s)=-\delta(1-u) c \exp (-\delta s)+r^{a} H^{*}(s) .
$$

This equation has a solution:

$$
\begin{aligned}
H^{*}(s) & =[\delta(1-u) c \exp (-\delta s)] /\left[r^{a}+\delta(1-u)\right] \\
& =[\delta c \exp (-\delta s)] /(i+\delta) \\
& =[\delta /(i+\delta)](\text { before-tax cash flow at age } s)
\end{aligned}
$$


Note that this user depreciation schedule is not related to the purchase price of the asset. Such a relationship will be a derived consequence of market equilibrium. The sum of all depreciation allowances according to this formula is given by

$$
v(0)=\int_{0}^{\infty}[\delta c \exp (-\delta \xi)] /(i+\delta) d \xi=c /(i+\delta) .
$$

The right-hand side is the purchase price, $q$, if $q(i+\delta)=c$, the equilibrium relationship in the absence of taxes. And in this case the economic depreciation to the holder is equal to replacement cost depreciation, given by expression 2 . If this relationship does not hold, the depreciation allowances will sum to a total different from the purchase price.

THE PROBLEM OF THE INVESTMENT CREDIT. This reasoning and the calculations that went before it are based implicitly on the mathematical assumption that $v(s)$ is a differentiable function. This assumption seems safe enough for all the features of the tax system except the investment tax credit. Thus expression 3 correctly describes the cash flow except at the moment of purchase, when there is an additional lump sum accumulation (an infinitely high cash flow for an instant) equal to the rebated investment tax credit. Similarly expression 4 is correct for $s$ greater than zero, but $v(0)$ does not correctly describe the value of a new asset to the holder. That value depends on the investment subsidy and its tax treatment.

One may think of the purchaser of an asset at price $q$ as receiving with the asset a coupon good for $k q$ in cash. Neglecting the question of whether there is enough tax liability to collect $k q$ (because under present U.S. law the credit is only usable to pay taxes), there are two ways of viewing this coupon. First, it may be ignored for tax purposes, in which case presumably the decline in asset value that takes place when the owner tears off the coupon and cashes it will also be disallowed as a deduction, even though it reflects a real fall in asset value to the holder. ${ }^{16}$ Second, the coupon value may be taken into taxable receipts, in which case the associated decline in asset value will also be recognized for tax purposes.

Both approaches have the same effect on the net-of-tax cash flow of the purchaser of the asset. Therefore let $V$ denote the value to the holder when the true depreciation to the holder is used for tax pur-

16. This is the treatment under the Long Amendment (see note 2). 
poses, and when either of the treatments above is applied to the tax credit. Then

$$
V=k q+v(0)
$$

and, using expression 6, equilibrium implies

$$
\begin{aligned}
V & =q \\
(1-k) q & =v(0) \\
c / q & =(1-k)(i+\delta) .
\end{aligned}
$$

Hence from expression 5, in equilibrium

$$
H^{*}(s)=(i-k) \delta \exp (-\delta s)
$$

Several conclusions may be drawn from this exploration of economic depreciation to the holder, none perhaps wholly unexpected. First, in equilibrium the "basis" for tax depreciation purposes, $v(0)$, is the net of credit price to the buyer, $(1-k) q$, either because the subsidy is not taken into taxable receipts and not allowed as an immediate write-off or because the subsidy is taken into taxable receipts and immediately deducted. Either approach accurately reflects the path of asset value to the owner and leads to a sum of depreciation allowances equal to the appropriate cost of the asset. Second, given this use of true depreciation, the tax rate has no effect on the equilibrium relationship between the rental cost of capital, $c$, and the price of a newly produced machine, $q$, except as it may influence the rate of interest, $i$. Third, the investment credit does enter the equilibrium condition in such a way as to influence the durability of assets emerging, even though the "correct" basis for depreciation is used. This conclusion brings me back to the principal concern of this paper.

\section{Efficiency and the Durability of Assets}

What is the requirement of efficiency in the allocation of investment at a given instant among machines of different durabilities? For simplicity I concentrate on steady states where the relevant marginal productivities can be regarded as constant over time. The question can then be rephrased: how should investment be allocated so as to obtain the highest sustainable flow of net output? 
To answer this question, consider the perpetuity obtainable by sacrificing a unit of consumption to purchase an asset of type $\delta$ and subsequently reinvesting sufficient amounts of the proceeds to keep net output constant. The way to do this is to reinvest the replacement cost depreciation from the gross yield. By doing this it is possible to maintain a steady flow of $\left(c \delta / q_{\delta}-\delta\right)$ where $c_{\delta}$ is here interpreted as the consumption-good flow of output from the new machine, and $q_{\delta}$ is taken to be the consumption-good cost of a machine of type $\delta .^{17}$ (Note the shift from price to real productivity and cost concepts.)

Thus at least if attention is confined to constant net output "steady state" paths, efficiency in the allocation of each instant's investment requires

$$
c_{\delta} / q_{\delta}-\delta=c_{\delta^{\prime}} / q_{\delta^{\prime}}-\delta^{\prime}
$$

if both types $\delta$ and $\delta^{\prime}$ are employed.

THE INVESTMENT TAX CREDIT AND EFFICIENCY WITH TRUE HOLDER'S DEPRECIATION. In order to assess the efficiency implications of various rules for the investment credit, it is necessary to consider the relationship between the marginal productivity of machines, $c \delta$, and the marginal consumption good cost, $q_{\delta}$, of the immediately preceding analysis and the rental price of machines, $c$, and the market price, $q$, of a machine in competitive equilibrium. To keep the analysis within manageable bounds I make the usual growth-model assumption that the production process generates output that is either immediately consumable or convertible to machines of various types (identified by $\delta$ ) on fixed terms (depending possibly on the stock or

17. To demonstrate this proposition, let $I(t)$ be the amount reinvested in asset type $\delta$ at time $t$, where the whole process is regarded as starting at time $0 . I(t)$ will be the difference between the gross yield from the initial investment plus subsequent reinvestment and $c_{\delta} / q_{\delta}-\delta$. It will thus satisfy

$$
I(t)=\int_{0}^{t} I(\xi) \frac{c_{\delta}}{q_{\delta}} e^{-\delta(t-\xi)} d \xi+\frac{c_{\delta}}{q_{\delta}} e^{-\delta t}-\left(\frac{c_{\delta}}{q_{\delta}}-\delta\right) .
$$

One may quickly verify by substitution that the solution to this integral equation is given by

$$
I(t)=\delta .
$$

That is, the program of constantly reinvesting the depreciation flow maintains gross output constant and thus maintains net output at $c_{\delta} / q_{\delta}-\delta$. To obtain any higher net output flow would require at least for some finite time accepting a lower net output flow. 
rate of production of the machine type in question). This means that both $c$ and $q$ can be regarded as measuring correctly the consumption opportunity cost of, respectively, the use and the construction of a machine. Since I am now concerned with machines of different durabilities, furthermore, I refine the price notation, and let $c \delta$ and $q \delta$ represent, respectively, the rental price of a unit of type $\delta$ machine services, and the price of one new type $\delta$ machine.

Under these conditions efficiency in investment can be identified with the equating of the before-tax rate of return (internal rate of return) from investment. This internal rate of return on type $\delta$ is given by

$$
r_{\delta}=c_{\delta} / q_{\delta}-\delta .
$$

Condition 7 shows that when $k=0$ this requirement is satisfied in equilibrium, regardless of the proportional tax rate, $u .^{18}$

When $k$ is not zero, condition 7 says that $c \delta / q_{\delta}-\delta=(1-$ $k) i-k \delta$. While $i$ is the same for all asset types, $\delta$ obviously is not.

Consider now the question of the relationship between asset durability and investment credit needed (when all assets display exponential capacity decay) to obtain efficiency in the presence of the credit. Because efficiency requires $c_{\delta} / q_{\delta}-\delta$ to be the same for all $\delta$, formula 7 can be used to express the requirement for $k$ :

$$
c / q-\delta=(1-k) i+(1-k) \delta-\delta=r,
$$

where $r$ is the internal rate of return common to all investments in an efficient program. Let $k(\delta)$ be the relationship between tax credit and durability required for efficiency. Then, solving formula 9 for $k(\delta)$ explicitly,

$$
k(\delta)=1-(r+\delta) /(i+\delta)
$$

is obtained.

As expected, the subsidy must increase with durability (decline with $\delta$ ) in order to obtain neutrality, with a zero subsidy for a zero life asset $(\delta=\infty)$. The "right" subsidy for each durability cannot, however, be specified in advance unless one can correctly anticipate the equilibrium interest rate.

18. This is the point established in Samuelson, "Tax Deductibility of Economic Depreciation." 


\section{Point Input, Point Output, and Related Investment Models}

To explore the effect of varying the exponential decay assumption I consider in this section the cases of (1) point input, point output and (2) point input, constant flow output production.

\section{Point Input, Point Output}

The assumption here, as it was implicitly in the previous section, is a homogeneous output that can either be consumed or invested. In this case, however, one cannot naturally associate units such as "number of machines" with investment. Consequently it will be simpler to consider a unit investment of type $d$ as costing one unit of consumption and yielding $y_{d}$ units of consumption $d$ time units later. This is to be understood as the entire return, liquidating the investment.

EFFICIENCY AND EQUILIBRIUM. The efficiency condition in this model, corresponding to condition 8 in the exponential decay model, may be derived by noting that the time pattern of an investment with returns after, say, two periods can be reproduced by investment in a one-period project together with reinvestment of all proceeds for a further period. Generalizing, this requires for all $d$ and $d^{\prime}$ representing investments actually undertaken in positive amounts

$$
y_{d}=\left(y_{d^{\prime}}\right)^{d / d^{\prime}} .
$$

The internal rate of return, $r_{d}$, associated with an investment in form $d$ is given by

$$
\exp \left(r_{d} d\right)=y_{d}
$$

or

$$
r_{d}=\ln y_{d} / d
$$

It will be immediately verified from formula 10 that efficiency implies equalizing the internal rate of return on investment opportunities pursued. In the absence of taxes, wealth maximizing capitalists will equate the internal rate of return at all investment margins to the rate of interest;

$$
i=r_{d}
$$

for all $d$, thus satisfying necessary condition 10 for efficiency. 
THE EFFECT OF AN INVESTMENT CREDIT. It will simplify the analysis of the effect of an investment tax credit if one takes for granted the proposition that if correctly calculated economic depreciation is used for tax purposes, tax rates do not upset the efficiency of market equilibrium in the sense of condition 10 . The effect of a credit at percentage rate $k$ is then to change the market equilibrium in condition 12 to

$$
i=r_{d}^{a}
$$

where $r_{d}^{a}$ is the after-credit rate of return from investment in asset type $d$, given by

$$
\begin{aligned}
r_{d}^{a} & =\ln \left[y_{d} /(1-k)\right] / d \\
& =r_{d}-[\ln (1-k)] / d .
\end{aligned}
$$

If expression 14 is used, equilibrium condition 12 can be rewritten:

$$
r_{d}=i+[\ln (1-k)] / d .
$$

As in the previous model, the rate of credit, $k$, must be varied with the durability of assets (interpreted here as the time, $d$, between point investment and point return) to assure satisfaction of efficiency condition 10. Unlike the previous case, there is in this model a method for doing this independently of the equilibrium rate of interest: $k$ need simply be varied to maintain the constancy of $\ln (1-k) / d$.

An explicit expression for the schedule, $k(d)$, of credits necessary to assure a given common before-subsidy rate of return, $r$, can be obtained by solving expression 15 to obtain

$$
k(d)=1-\exp [(r-i) d] .
$$

\section{Point Input, Constant Flow Output}

In the last special investment model I assume that in return for a point input of one dollar of forgone consumption a constant flow of output at rate $x_{T}$ can be generated from the instant of investment until a time $T$ periods later, at which point the investment is exhausted.

To analyze the efficiency conditions for a program of investments of different durabilities it will be convenient to assume that the point input, point output opportunities are also available. Since a point input, flow output pattern can be reproduced by an appropriate mixture of point input, point output projects, efficiency requires that the cost 
of the two methods of obtaining the same effect be the same. In particular, by undertaking $x_{T} / y_{d}$ units of type $d$ point input, point output investment for all $d$ between 0 and $T$, a steady output flow of $x_{T}$ per period is produced over the interval. This investment program costs

$$
\int_{0}^{T}\left(x_{T} / y_{\xi}\right) d \xi
$$

and efficiency requires this to equal 1 . Let $r$, defined as in expression 11 , denote the common internal rate of return on all point input, point output projects in an efficient program. Then, using expression 16, efficiency in the point input, constant flow output case requires

$$
x_{T} \int_{0}^{T} \exp (-r \xi) d \xi=1
$$

for all "durabilities," $T$, in use. This is precisely the requirement that the internal rate of return, $r_{T}$, defined in expression 18 also equal $r$ for all $T$ employed.

$$
x_{T} \int_{0}^{T} \exp \left(-r_{T} \xi\right) d \xi=1 .
$$

In the absence of investment subsidies, wealth maximization will lead to the equating of all investment returns to the market rate of interest, by the usual arguments. Let $r_{T}^{a}$ denote the after-subsidy internal rate of return, defined by

$$
x_{T} \int_{0}^{T} \exp \left(-r_{T}^{a} \xi\right) d \xi=1-k
$$

Equilibrium now requires

$$
i=r_{T}^{a}
$$

for all durabilities, $T$, employed.

It will not in general be true that the before-subsidy internal rate of return associated with this equilibrium will be the same for all $T$, as required for efficiency. Suppressing the associated algebra, one can write the variation in $k$ with $T$ required to assure satisfaction of expression 17 as

$$
\begin{aligned}
k(T) & =1-\{[1-\exp (-i T)] / i\} /\{[1-\exp (-r T)] / r\} \\
& =1-(r / i)[1-\exp (-i T)] /[1-\exp (-r T)],
\end{aligned}
$$


where $r$ is the common social rate of return on real investment and $i$ is the market rate of interest, which by expression 19 also equals the rate of return to the investor.

As in the two previous models, efficiency requires the subsidy rate to increase with the life of the investment. Further, as in the exponential decay model, but not as in the point input, point output case, it is necessary to know the equilibrium situation-that is, to know $i$-in order to obtain the rule for the efficiency-preserving relationship between credit and asset durability.

\section{Summing Up}

The foregoing analysis gives a formal demonstration of two general principles: (1) that a credit varying with the durability of the investment is required for neutrality of the subsidy with respect to this aspect of investment choice; and (2) that a different structure of such credits will in general be necessary for different patterns of returns. Table 1 suggests the importance of these principles as a practical matter. This table illustrates the structure of credits required to induce a common before-credit rate of 8 percent on investments of various types and durabilities while providing the investors with a common 10 percent after-credit (before income tax) rate of return in every case.

Unfortunately it is difficult to relate these illustrative figures to actual tax practice or to draw policy guidance from them beyond what emerges from the qualitative argument of the theory. Indeed, the theoretical argument is less than satisfactory. Apart from their being cast in a steady state framework, the theoretical conclusions have the shortcoming of being based on the assumption that the market cost of investments correctly measures the consumption goods forgone. ${ }^{19}$ But presumably the relative market prices of various investment and consumer goods are influenced by the investment tax credit.

This issue is too complicated to do more than suggest the nature of the problem here. Suppose, for example, that a machine of some type can be produced either directly by conversion of consumption goods or indirectly by the machine itself. The higher the investment credit,

19. All of this assumes that the second-best rules call for production efficiency. Even this rule may not hold under some circumstances; see J. E. Stiglitz and P. Dasgupta, "Differential Taxation, Public Goods, and Economic Efficiency,"- Review of Economic Studies, vol. 38 (April 1971), pp. 151-74. 
Table 1. Illustrative Schedule of Durability-Neutral Investment Tax Credit"

Rates in percent

\begin{tabular}{|c|c|c|c|c|c|}
\hline \multicolumn{2}{|c|}{ Exponential depreciation $^{b}$} & \multicolumn{2}{|c|}{ Point input, point output } & \multicolumn{2}{|c|}{$\begin{array}{l}\text { Point input, constant } \\
\text { flow output }\end{array}$} \\
\hline $\begin{array}{c}\text { Durability } \\
\text { parameter } \\
\delta\end{array}$ & $\begin{array}{c}\text { Neutral } \\
\text { investment } \\
\text { credit rate } \\
k(\delta)\end{array}$ & $\begin{array}{l}\text { Durability } \\
\text { parameter } \\
\quad d\end{array}$ & $\begin{array}{c}\text { Neutral } \\
\text { investment } \\
\text { credit rate } \\
k(d)\end{array}$ & $\begin{array}{c}\text { Durability } \\
\text { parameter } \\
T\end{array}$ & $\begin{array}{c}\text { Neutral } \\
\text { investment } \\
\text { credit rates } \\
k(T)\end{array}$ \\
\hline 1 & 1.8 & 1 & 2.0 & 1 & 1.0 \\
\hline $1 / 2$ & 3.3 & 2 & 3.9 & 2 & 1.9 \\
\hline $1 / 3$ & 4.6 & 3 & 5.8 & 3 & 2.8 \\
\hline $1 / 4$ & 5.7 & 4 & 7.7 & 4 & 3.7 \\
\hline $1 / 5$ & 6.6 & 5 & 9.5 & 5 & 4.5 \\
\hline $1 / 7$ & 8.2 & 7 & 13.1 & 7 & 6.1 \\
\hline $1 / 10$ & 10.0 & 10 & 18.1 & 10 & 8.2 \\
\hline $1 / 15$ & 12.0 & 15 & 25.9 & 15 & 11.1 \\
\hline $1 / 20$ & 13.3 & 20 & 33.0 & 20 & 13.3 \\
\hline 0 & 20.0 & $\infty$ & 100.0 & $\infty$ & 20.0 \\
\hline
\end{tabular}

a. Under various assumptions about form and duration of return patterns, entries show investment credit required to generate a rate of return $(i)$ of 10 percent to the investor when the common underlying rate of return $(r)$ is 8 percent.

b. This can be interpreted as assuming the asset disappears at rate $\delta e^{-\delta s}$, where $s$ is the time since construction.

c. A unit investment at time 0 yields $y_{d}$ at time $d$.

d. A unit investment at time 0 yields a steady flow $x r$ of output until time $T$.

e. $k(\delta)=1-(r+\delta) /(i+\delta)$.

f. $k(d)=1-\exp (r-i) d$.

g. $k(T)=1-(r / i)[1-\exp (-i T)] /[1-\exp (-r T)]$.

the lower will be the equilibrium rental price of machines. As a result, machines will increasingly be produced by other machines rather than by direct conversion of consumption goods. The outcome is a tax-induced inefficiency in the production of machines. If the machine-produced machine differs from the directly-converted-fromconsumption-goods machine with respect to durability, it may be possible to offset this inefficiency through appropriate useful life discrimination in the credit rules.

There is another shortcoming in the theoretical argument that appears in many efficiency analyses: the absence of guidance on how much difference mistakes make. Remedying this defect seems out of the question, however, as it would require a knowledge of the elasticities of substitution of each machine type for others in production, as well as of the production conditions of the machines themselves. (Remember that the term "machine" is used here to represent all forms of investment.) 
Table 2. Illustrative Schedule of Neutral Investment Credit under "Plausible" Depreciation Assumption

\begin{tabular}{cccc}
\hline $\begin{array}{c}\text { Durability } \\
\text { parameters }\end{array}$ & $\begin{array}{c}\text { Neutral } \\
\text { Useful life } \\
\text { (years) }\end{array}$ & $\begin{array}{c}\text { investment } \\
\text { credit rate } \\
\text { (percent) }\end{array}$ & $\begin{array}{c}\text { Present U.S. } \\
\text { (aw credit } \\
\text { (percent) }\end{array}$ \\
\hline $2 / 3$ & 3 & 2.7 & 3.3 \\
$2 / 5$ & 5 & 4.0 & 6.7 \\
$2 / 7$ & 7 & 5.1 & 10.0 \\
$1 / 5$ & 10 & 6.5 & 10.0 \\
$1 / 6$ & 12 & 7.3 & 10.0 \\
$2 / 15$ & 15 & 8.4 & 10.0 \\
$1 / 10$ & 20 & 9.9 & 10.0 \\
\hline
\end{tabular}

Source: Based on Emil Sunley, Jr., "Tax Neutrality between Capital Services Provided by Long-Lived and Short-Lived Assets," in U.S. Department of the Treasury, OTA Papers, vol. 1 : Compilation of OTA Papers (GPO, 1978), p. 15. Investor obtains 10 percent return (before tax) on all asset classes; beforecredit return is 8 percent on all assets. For details of assumptions see text.

a. Exponential decay rate.

b. Neglects extra credit for employee stock ownership plan.

If these technical problems are overlooked, practical difficulties in using the figures in table 1 remain. For one thing, it is not clear how one should associate the various durability parameters of the table to the concept of "useful life" in U.S. tax law. Does an asset exponentially decaying at 10 percent a year (average life, ten years; half life, seven years) have a longer or shorter useful life than one producing all its output exactly ten years after construction or one producing a constant flow output for, say, fifteen years? Second, allowance must be made for the fact that the figures in the table are based on requiring a deduction of investment credit from the basis for depreciation and using true economic depreciation for tax purposes.

Basing his calculations on an unpublished paper by T. Nicholaus Tideman, Sunley derived the investment credit schedule required for neutrality (in the sense analyzed here) assuming (1) original purchase price used as the basis for depreciation; (2) exponential decay of assets; (3) sum-of-years method of depreciation for tax purposes, interpreting $2 / \delta$ as the useful life of an asset decaying at rate $\delta$; and (4) a marginal tax rate of 0.48 (needed because tax depreciation is different from economic depreciation). ${ }^{20}$ Sunley's neutral credit schedule is shown in table 2 . It is interesting and somewhat surprising

20. See Sunley, "Tax Neutrality between Capital Services Provided by LongLived and Short-Lived Assets"; and T. Nicolaus Tideman, "Refinements in the Formula for the Price of Capital Services and Their Application to Tax Neutrality" (1975). 
how similar the neutral credit rates are under the more realistic assumptions made by Sunley and those for exponential decay in table 1 . The fit of both of these with present law also appears better than might have been expected, and it looks even better if one measures useful life by the average or expected life of the asset, $1 / \delta$, instead of $2 / \delta$.

On the other hand, under the exponential depreciation assumption there is clearly a bias in present law against the long-lived assets, and there is no way of assessing the importance of other patterns of investment returns. These are but two relatively unimportant reasons for a substantial revision in the way capital income is measured and taxed. But this is the subject of another paper. ${ }^{21}$

21. The results of this paper and those of Arnold Harberger's paper in this volume are complementary. I show that if depreciation is allowed on the net price of a capital good-the purchase price less the investment tax credit-then a neutral investment credit depends on the pattern of true economic depreciation and rises with durability. Harberger shows that if depreciation is allowed on $100(1-k / t)$ percent of the purchase price of a capital good (where $k$ is the investment credit rate and $t$ is the income tax rate), then a constant investment tax credit is neutral. To illustrate, if the tax rate is 40 percent and the credit is 10 percent, then the credit is neutral with respect to durability if the firm is permitted tax depreciation equal to true economic depreciation on 75 percent of the value of the capital good; if the firm can depreciate any larger fraction of the value, and in particular if it can depreciate 90 percent as under the Long Amendment, then a constant credit favors short-Jived capital goods and a neutral credit must rise with durability. 